\title{
Iron Coordination by Catechol Derivative Antioxidants
}

\author{
Teruyuki Kawabata,* Victor Schepkin, \\ Nobuya Haramaki, Ratna S. Phadke† and Lester Packer \\ Membrane Bioenergetics Group, Department of Molecular and \\ Cell Biology, University of California, Berkeley, CA 94720-3200, U.S.A.
}

\begin{abstract}
Iron complexes of nitrocatechols with different substituent groups $\left[1:-\mathrm{CH}=\mathrm{CR}_{2} ; 2\right.$ : $-\mathrm{CH}_{2}-\mathrm{CHR}_{2} ; 3$ : $\left.-\mathrm{CH}=\mathrm{CR}^{\prime}\left(\mathrm{R}^{\prime \prime}\right)\right]$ were synthesized and their effects on iron-induced free radical reactions of biological importance investigated. Catechol and nitrocatechol derivatives effectively inhibited iron-induced lipid peroxide-dependent lipid peroxidation. In the Fenton-like reaction, iron-catechol generated hydroxyl radicals more strongly than did iron citrate, and iron-nitrocatechol derivative 2 generated a small amount of hydroxyl radicals. The iron complexes of derivatives 1 and 3 did not generate hydroxyl radicals. Iron-catechol had the highest ratio of reduction to oxidation rate constants and the second was iron-nitrocatechol 2, suggesting that iron chelated by nitrocatechols 1 and 3 may be most difficult to reduce. To elucidate the structure and physical properties of the iron complexes, UV/vis absorption spectroscopic, ESR and ${ }^{1} \mathrm{H}$ NMR studies were performed in aqueous and DMSO solutions. In aqueous solution at $\mathrm{pH} 7.4$, iron complexes of the nitrocatechol derivatives were high-spin tris(nitrocatecholato)ferrate(III) with a characteristic ligand-to-metal charge transfer absorbance $\left(\pi \rightarrow \mathrm{d}_{\pi}\right)$. The $\lambda_{\max }$ of iron-nitrocatechol derivative 2 was shorter than those of iron-nitrocatechol derivatives 1 and 3 , suggesting that the reduction potential of iron-nitrocatechol 2 is higher than that of iron-nitrocatechols 1 and 3 . Nitrocatechol derivatives with a conjugation structure can sequester the chelated iron more effectively than catechol and the derivative without the conjugation against free radical generation by keeping the iron in the ferric state, probably because of the reduction potentials. BIOCHEM PHARMACOL 51;11:1569-1577, 1996.
\end{abstract}

KEY WORDS. chelation; lipid peroxidation; free radicals; reduction potential

It is well established that free radicals and active oxygen species are associated with many pathological conditions such as radiotherapy, ischemia-reperfusion, inflammation, and aging, where iron plays an inportant role by way of the generation of active oxygen species and free radicals [1-4]. Hydroxyl and alkoxyl radicals are believed to be major causative species for iron-induced free radical injuries in biological systems [5]:

$$
\mathrm{H}(\mathrm{L}) \mathrm{OOH}+\mathrm{Fe}^{2+} \rightarrow \mathrm{H}(\mathrm{L}) \mathrm{O}^{*}+\mathrm{OH}^{-}+\mathrm{Fe}^{3+}
$$

Although other reactive intermediates such as oxoferryl complex and binuclear peroxo complex are also proposed in the process of iron-catalyzed activation of oxygen [6-8], ferrous ion may be potentially much more dangerous than

\footnotetext{
* Corresponding author (and present address): Dr. Teruyuki Kawabata, Department of Pathology, Okayama University Medical School, 2-5-1 Shikata-cho, Okayama 700, Japan. Tel. +81-86-235-7145, Ext. 2330; FAX $+81-86-221-4743$.

† Permanent address: Chemical Physics, Tata Institute of Fundamental Research, Homi Bhabha Road, Bombay 400005, India.

Received 17 July 1995; accepted 26 December 1995.
}

ferric ion. Since iron exists as a chelated complex in biological conditions $[9,10]$, if iron can be kept ferric by a chelator under physiological conditions, the catalytic activity of iron for free radical reactions will be decreased, suggesting the significance of a low reduction potential of an iron chelator complex. Transferrin and desferal (methanesulfonate salt of desferrioxamine $B$, a siderophore of the hydroxamate type) are widely used for protection against iron-induced free radical injuries. They are strong chelators for iron $\left(\mathrm{p} K_{f} \approx 30\right),{ }^{\ddagger}$ and their iron complexes have much lower reduction potential $\left(\mathrm{E}^{\circ} \approx-0.3 \mathrm{~V}\right)$ than other iron chelators such as EDTA, citrate, and ADP [11].

From a clinical viewpoint, the kind of chelator necessary to sequester catalytic iron in biological systems is an important question for disease protection and therapy. First of

¥ Abbreviations: $K_{f}$, formation constant; $k$, rate constant; s, d, t, and br singlet, doublet, triplet, and broad; nitrocat, nitrocatechol derivative; TBARS, thiobarbituric acid reactive substance; DHLA, dihydrolipoic acid; DMPO, 5,5-dimethyl-1-pyrroline- $\mathrm{N}$-oxide; DMPO-OH, hydroxyl radical adduct of DMPO; DPPH, 2,2-di(4-tert-octylphenyl)-1. picrylhydrazyl; TMS, tetramethylsilane; TSP, sodium 3-trimethyl[2,2,3,3$\mathrm{D}_{4}$ lpropionate; and HOMO, highest occupied molecular orbital. 
$\mathrm{R}: \mathbf{1}$

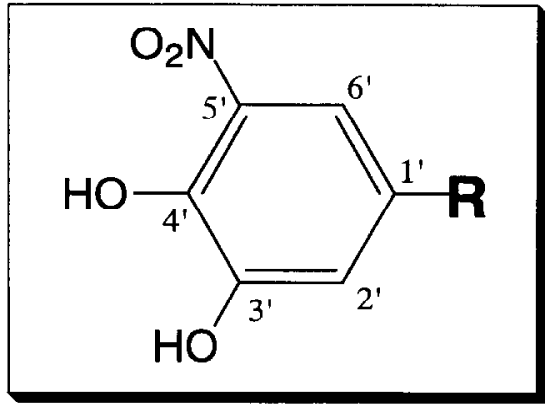

Nitropyrocatechol Chromophore

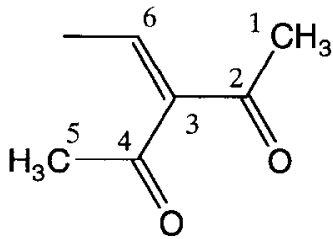

2

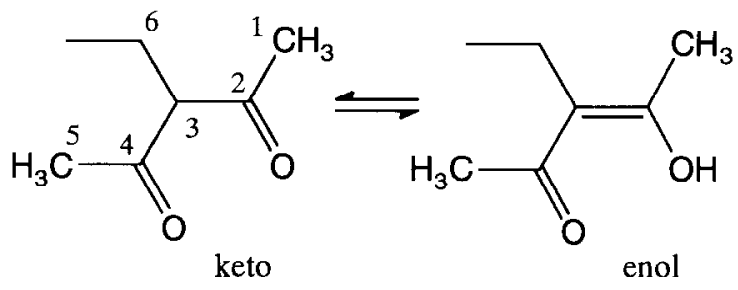

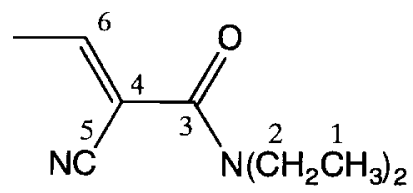

FIG. 1. Catechol derivative antioxidants. The catechol derivatives have nitropyrocatechol chromophores in common, and the tail portions were different between the derivatives. Key: (1) 3-(3,4-dihydroxy-5-nitrobenzylidene)-2,4-pentanedione, (2) 3-(3,4-dihydroxy-5-nitrobenzyl)-2,4-pentanedione, and (3) 2-cyano-3-(3,4-dihydroxy-5-nitrophenyl)-N,N-diethyl-2propenamide.

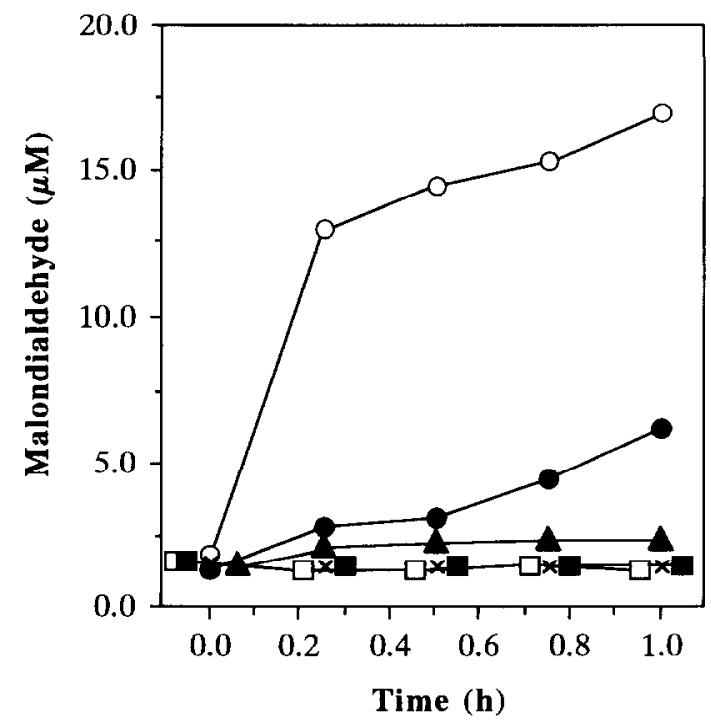

FIG. 2. Iron-induced lipid peroxide-dependent lipid peroxidation. Microsomes $(1.0 \mathrm{mg}$ protein $/ \mathrm{mL}$ ) were incubated with iron complexes of the nitrocatechol derivatives $(0.1$ $\mathrm{mM}$ iron and $0.3 \mathrm{mM}$ chelators) and ascorbate $(0.5 \mathrm{mM})$ in HEPES-saline (pH 7.4) at $37^{\circ}$, and lipid peroxidation was measured by the thiobarbituric acid method. Values are presented as malondialdehyde by using malonaldehyde bis(dimethyl acetal) as a standard. Key: (O-O) control; (Ocitrate; ( $\square-\square)$ derivative 1 ; $(\square-\square)$ derivative 2 ; $(x-x)$ derivative 3 ; and $(\boldsymbol{\Delta}-\boldsymbol{\Delta})$ catechol. Values present averages in duplicate. all, the chelator must form a stable iron complex to remove deleterious iron from biomolecules. However, in addition to thermodynamic stability, the reduction potential of the iron chelator is important for protection against ironinduced free radical injuries. Catechol-type chelators have large stability constants for iron and low reduction potentials $[12,13]$. Catcchol forms a thermodynamically stable complex with iron $\left(\log K_{f}=40\right)$ as a bidentate ligand [14] and has been crystallized as an octahedral complex [tris(catecholato)ferrate(III)] [15]. Catechol-type chelators are used as siderophores by microorganisms like hydroxamate-type chelators, such as desferrioxamine B [16], and may not be so toxic to cells. Recently, a nitrocatechol derivative [3-(3,4dihydroxy-5-nitrobenzylidene)-2,4-pentanedione] was reported to be a potent antioxidant $[17,18]$. The nitrocatechol derivative antioxidant was applied to ischemiareperfusion injuries of rat heart [19], in which we showed effective protection against the injuries and suggested some chelating effects of the derivative for protection in addition to the radical scavenging effects.

In the present study, iron-induced lipid peroxidation and hydroxyl radical generation were tested in the presence of nitrocatechol derivatives, and the oxidation and reduction rates of the iron chelated by the derivatives were also studied in aqueous solution. To elucidate the molecular environment around the iron, the physical properties of ironnitrocatechol derivative complexes were studied by UV/vis absorption, ESR and NMR spectroscopy. It was clarified that nitrocatechol derivatives formed catechol-type complexes with iron and were effective for the protection against iron-induced free radical reaction. 


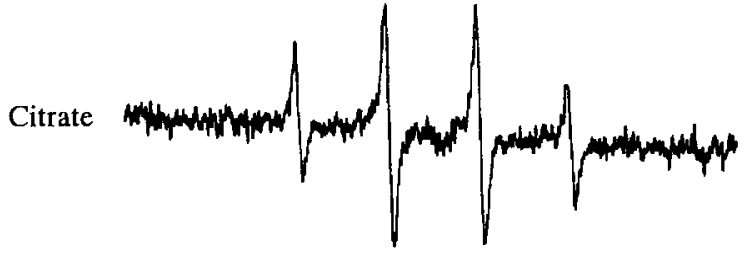

1

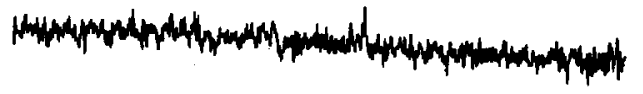

2

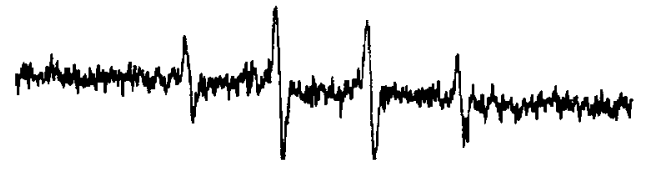

3
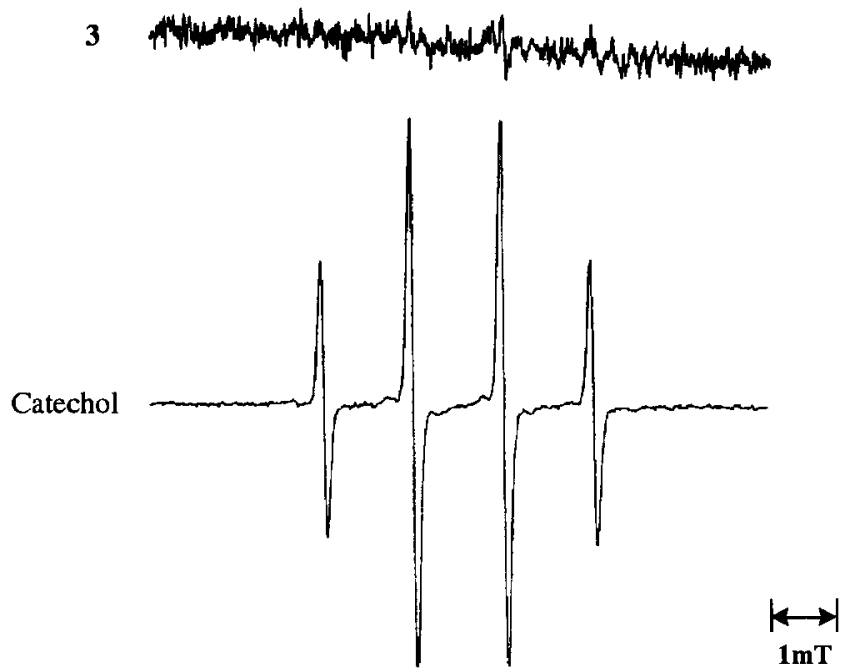

FIG. 3. ESR spin-trapping of hydroxyl radicals generated by iron complexes of nitrocatechol derivatives 1,2 , and 3 (shown in Fig. 1) and $\mathrm{H}_{2} \mathrm{O}_{2}$. The reaction was done at room temperature in the presence of iron complexes $(0.33 \mathrm{mM}$ iron and $1 \mathrm{mM}$ chelator), hydrogen peroxide $(500 \mathrm{mM})$, and DMPO $(100 \mathrm{mM})$. ESR spectra were taken $10 \mathrm{~min}$ after the addition of hydrogen peroxide. Gain: $5.0 \times 10^{5}$ except for catechol (gain: $1.0 \times 10^{5}$ ).

\section{MATERIALS AND METHODS \\ Reagents}

Nitrocatechol derivatives were gifts from Orion-Farmos Pharmaceuticals (Espoo, Finland) (Fig. 1): (1) 3-(3,4-dihydroxy-5-nitrobenzylidene)-2,4-pentanedione, ${ }^{1} \mathrm{H}$ NMR $\left(\mathrm{DMSO}_{-} \mathrm{d}_{6}\right) \delta 2.38(\mathrm{~s}, 3 \mathrm{H}), 2.26(\mathrm{~s}, 3 \mathrm{H}), 7.09(\mathrm{~d}, 1 \mathrm{H}), 7.57$ (s, $1 \mathrm{H}), 7.60$ (d, 1H), 10.7 (br, 1H); (2) 3-(3,4-dihydroxy5-nitrobenzyl)-2,4-pentanedione, keto(enol) type, ${ }^{1} \mathrm{H}$ NMR (DMSO-d $\left.{ }_{6}\right) \delta 2.07(\mathrm{~s}, 1 \mathrm{H}), 2.14(\mathrm{~s}, 1 \mathrm{H}), 2.92(\mathrm{~d}$, $1 \mathrm{H})(3.58(\mathrm{~d}, 1 \mathrm{H})), 4.25(\mathrm{t}, 1 \mathrm{H}), 6.93(\mathrm{~d}, 1 \mathrm{H})(6.89(\mathrm{~d}$, $1 \mathrm{H})), 7.21(\mathrm{~d}, 1 \mathrm{H})(7.10(\mathrm{~d}, 1 \mathrm{H})), 10.08(\mathrm{br}, 1 \mathrm{H})(16.86$ (br, 1H)); and (3) 2-cyano-3-(3,4-dihydroxy-5nitrophenyl)-N,N-diethyl-2-propenamide, ${ }^{1} \mathrm{H}$ NMR $\left(\mathrm{DMSO}_{-} \mathrm{d}_{6}\right) \delta 1.16(\mathrm{~s}, 6 \mathrm{H}), 3.41(\mathrm{~s}, 4 \mathrm{H}), 7.65(\mathrm{~s}, 1 \mathrm{H}), 7.76$ (d, 1H), $7.93(\mathrm{~d}, 1 \mathrm{H}), 10.92(\mathrm{br}, 1 \mathrm{H})$. Catechol, citrate (trisodium salt), deferoxamine methylate (Desferal),
HEPES, bovine serum albumin (fraction V, essentially fatty acid free) and DMSO were purchased from the Sigma Chemical Co. (St. Louis, MO). Malonaldehyde bis(dimethyl acetal), DMPO and gallium(III) nitrate hydrate were purchased from the Aldrich Chemical Co. (Milwaukee, WI). DMPO was used after purification with charcoal [20]. $\mathrm{D}_{2} \mathrm{O}$ and DMSO- $\mathrm{d}_{6}$ were from Wilmad (Buena, NJ) and $\mathrm{Fe}\left(\mathrm{NO}_{3}\right)_{3} \cdot 5 \mathrm{H}_{2} \mathrm{O}$ was from J. T. Baker Chemical (Phillipsburg, NJ). L-Ascorbic acid was obtained from Fisher Scientific (Pittsburgh, PA). All other reagents were analytical grade.

Male Sprague-Dawley rats (200-250 g) were obtained from Bantin \& Kingman (Fremont, CA) and acclimatized for at least 3 days with ad lib. access to standard laboratory food and water.

\section{Lipid Peroxidation of Rat Liver Microsomes}

Rat liver was homogenized in a medium (220 mM mannitol, $70 \mathrm{mM}$ sucrose, $2 \mathrm{mM}$ IILPES, and $0.5 \mathrm{~g} / \mathrm{L}$ bovine serum albumin) on ice, and then microsomes were prepared by centrifugation [21]. The protein concentration was measured as described by Lowry et al. [22], and microsomes (10.0 $\mathrm{mg}$ protein $/ \mathrm{mL}$ ) were resuspended in HEPES-saline (20 mM HEPES and $150 \mathrm{mM} \mathrm{NaCl}, \mathrm{pH} 7.4$ ). Ten microliters of $\mathrm{Fe}\left(\mathrm{NO}_{3}\right)_{3}(10 \mathrm{mM}$ in $0.1 \mathrm{~N} \mathrm{HCl})$ and $300 \mu \mathrm{L}$ of nitrocatechol derivative or citrate (1 $\mathrm{mM}$ in HEPES-saline) were added to $490 \mu \mathrm{L}$ of HEPES-saline, and then $100 \mu \mathrm{L}$ of

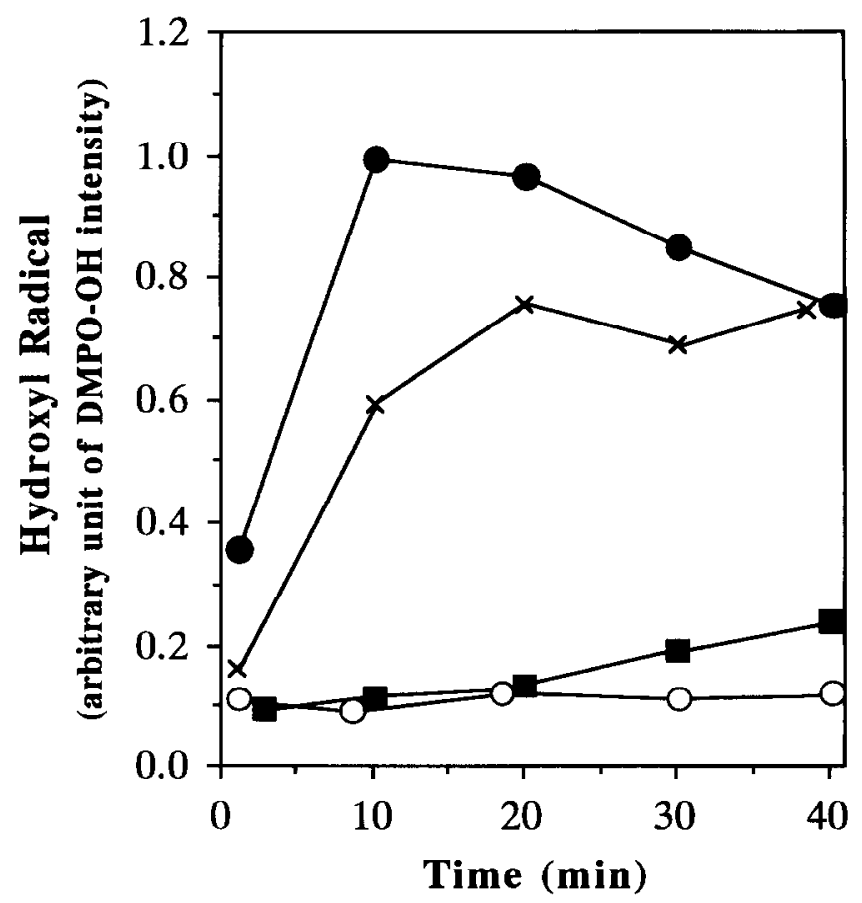

FIG. 4. Hydroxyl radical generation by iron complexes of nitrocatechol derivatives and $\mathrm{H}_{2} \mathrm{O}_{2}$. The intensity of the second line of DMPO.OH produced under the same conditions described in the legend of Fig. 3 was followed at room temperature. Key: (O-O) citrate; $(U-\cup)$ derivative $1 ;(x-x)$ derivative 2 ; and ( $\square-\square$ ) derivative 3 . Values present averages in duplicate. 
TABLE 1. Oxidation and reduction rate constants of iron in nitrocatechol derivative complexes

\begin{tabular}{lccc}
\hline & $\mathbf{k}_{\mathbf{O x}}\left(\mathbf{\times 1 0 ^ { - 3 }} \mathbf{M}^{-\mathbf{1}} \cdot \mathbf{s e c}^{-\mathbf{1}}\right)$ & $\mathbf{k}_{\mathbf{R d}}\left(\mathbf{M}^{-\mathbf{1}} \cdot \mathbf{s e c}^{-\mathbf{1}}\right)$ & $\mathbf{k}_{\mathbf{R d}} / \mathbf{k}_{\mathbf{O x}}\left(\mathbf{\times 1 0 ^ { 3 }}\right)$ \\
\hline Citrate & $0.56 \pm 0.07$ & $0.84 \pm 0.03$ & 1.5 \\
$\mathbf{1}$ & $3.15 \pm 0.06$ & $0.20 \pm 0.00$ & 0.063 \\
$\mathbf{2}$ & $2.89 \pm 0.01$ & $0.20 \pm 0.01$ & 0.070 \\
$\mathbf{3}$ & $2.91 \pm 0.07$ & $0.18 \pm 0.02$ & 0.062 \\
Catechol & $2.34 \pm 0.04$ & $1.70 \pm 0.16$ & 0.73 \\
\hline
\end{tabular}

The rate constants of oxidation $\left(k_{\mathrm{Ox}}\right)$ and reduction $\left(k_{\mathrm{Rd}}\right)$ were measured in HEPES-saline ( $\left.\mathrm{pH} 7.4\right)$ at $25^{\circ}$, assuming a saturated oxygen concentration of $253 \mu \mathrm{M}$, and the rate constants were calculated as a second-order reaction. Each value is the mean $\pm \mathrm{SD}$ of four experiments.

microsomes was added and mixed. The reaction was started by the addition of $100 \mu \mathrm{L}$ of ascorbate $(5 \mathrm{mM}$ in distilled water), and the reaction mixture was incubated at $37^{\circ}$. The reaction was stopped by the addition of $1.0 \mathrm{~mL}$ of Desferal ( $1 \mathrm{mM}$ in distilled water), and TBARS was measured by the method of Ohkawa et al. [23]. Malonaldehyde bis(dimethyl acetal) was used as a standard for TBARS.

\section{ESR Spin-Trapping}

DMPO $(100 \mathrm{mM})$ was used as a spin trap to detect hydroxyl radicals [6]. The reaction was initiated by the addition of hydrogen peroxide $(500 \mathrm{mM})$ to ferric complexes (1 mM derivative and $0.33 \mathrm{mM}$ iron). ESR spectra were recorded by a Varian E $109 \mathrm{E}$ spectrometer using $50-\mu \mathrm{L}$ capillary tubes at room temperature under the following conditions: microwave power, $20 \mathrm{~mW}$; gain, $5.0 \times 10^{5}$; modulation, $0.125 \mathrm{mT}$; scanning field, $348 \pm 5 \mathrm{mT}$; sweep time, $50 \mathrm{sec}$; time constant, $100 \mathrm{msec}$.

\section{Oxidation and Reduction Rates of the Iron}

A Clarke-type oxygen electrode was used at $25^{\circ}$, assuming a saturated oxygen concentration of $253 \mu \mathrm{M}$. For the oxidation rate, $10 \mu \mathrm{L}$ of $\mathrm{FeSO}_{4}(50 \mathrm{mM})$ in $0.001 \mathrm{~N} \mathrm{HCl}$ was added to $1.5 \mathrm{~mL}$ of nitrocatechol derivative $(1 \mathrm{mM})$ in HEPES-saline ( $\mathrm{pH} 7.4$ ), and oxygen consumption was measured. The oxidation rate was calculated from the stoichiometry:

$$
\mathrm{Fe}^{2+}+1 / 4 \mathrm{O}_{2}+\mathrm{H}^{+} \rightarrow \mathrm{Fe}^{3+}+1 / 2 \mathrm{H}_{2} \mathrm{O}
$$

The oxidation rate constant $\left(k_{O x}\right)$ was calculated by divid- ing the oxidation rate of ferrous ion by iron and oxygen concentrations.

For the reduction rate, $10 \mu \mathrm{L}$ of $\mathrm{Fe}\left(\mathrm{NO}_{3}\right)_{3}(50 \mathrm{mM})$ in $0.001 \mathrm{~N} \mathrm{HCl}$ was mixed with $1.5 \mathrm{~mL}$ of nitrocatechol derivative $(1 \mathrm{mM})$ in HEPES-saline ( $\mathrm{pH} 7.4)$, and then $10 \mu \mathrm{L}$ of dihydrolipoic acid (1.5 $\mathrm{M}$ in ethanol) was added to the reaction mixture. The oxygen consumption was measured, and the reduction rate was calculated from the stoichiometry [24]:

$$
\begin{aligned}
& \mathrm{Fe}^{3+}+1 / 2 \mathrm{DHLA} \rightarrow \mathrm{Fe}^{2+}+1 / 2 \mathrm{LA}+\mathrm{H}^{+} \\
& \mathrm{Fe}^{2+}+1 / 4 \mathrm{O}_{2}+\mathrm{H}^{+} \rightarrow \mathrm{Fe}^{3+}+1 / 2 \mathrm{H}_{2} \mathrm{O}
\end{aligned}
$$

Since the latter rate was much more rapid than the former, the reduction rate of iron is approximately equal to the oxygen consumption. The rate constant $\left(k_{\mathrm{Rd}}\right)$ was calculated by dividing the rate by iron and DHLA concentrations.

\section{UV/vis Absorption Spectrophotometry}

UV/vis spectra of ferric complexes of nitrocatechol derivatives were recorded by a Perkin-Elmer spectrophotometer (Norwalk, CT) at room temperature. To determine the molar ratio of iron to nitrocatechol derivative, Job's plotting was used in HEPES-saline ( $\mathrm{pH} 7.4$ ) and DMSO. Spectra were recorded, changing the molar ratio of ferric ion and the nitrocatechol derivatives, but keeping the total amount of iron and derivatives constant $(0.1 \mathrm{mM}$ in HEPES-saline; $10 \mathrm{mM}$ in DMSO).

\section{ESR Spectroscopy}

ESR spectra were recorded using a Bruker IBM ER200 DSRC electron spin resonance spectrometer at $200^{\circ} \mathrm{K}$. Ali-

TABLE 2. Properties of electronic absorption spectra of iron complexes of nitrocatechol derivatives in HEPES-saline (pH 7.4) and DMSO

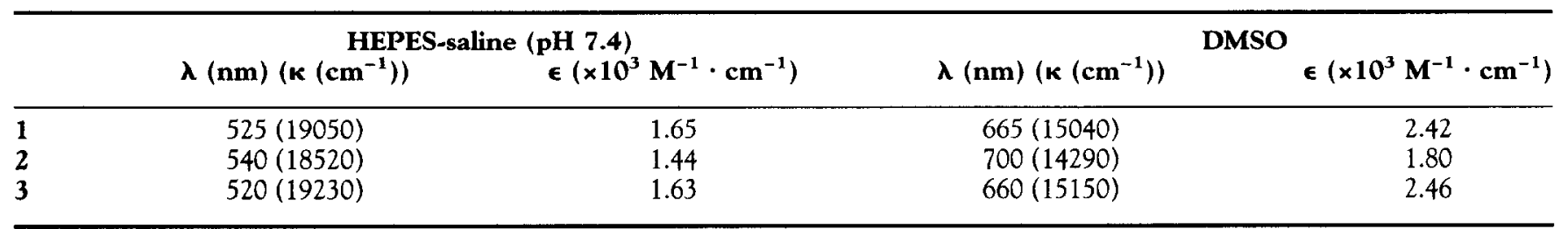

The wave length $(\lambda)$ and wave number $(\kappa)$ of ligand-to-metal charge transfer of iron nitrocatechol complexes were measured at room temperature in the buffer and DMSO. The molar extinction coefficient $(\epsilon)$ is presented as iron concentration. 


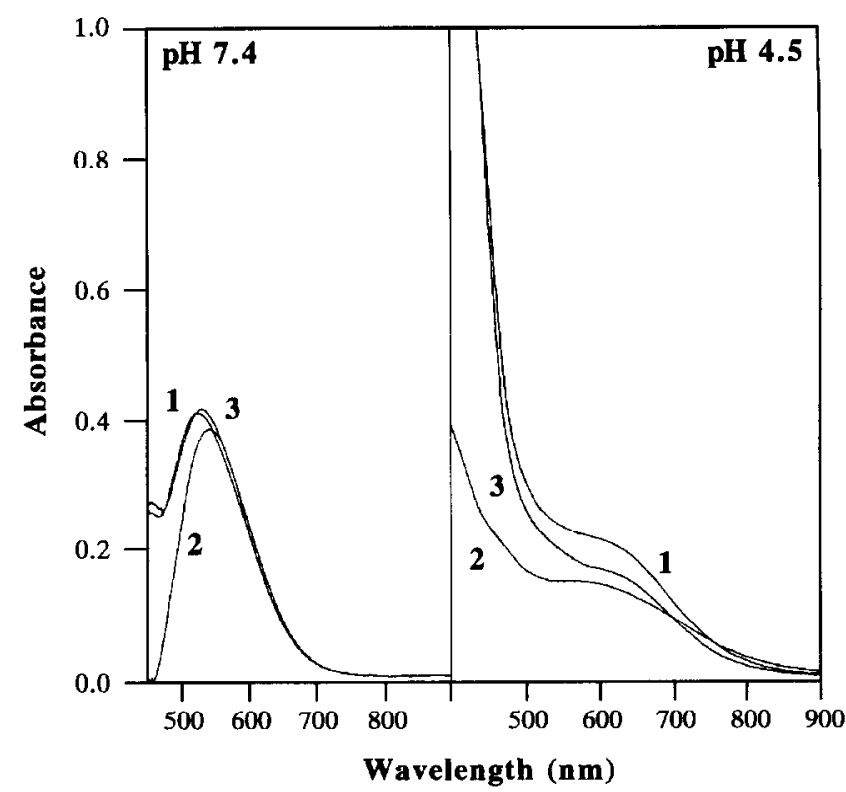

FIG. 5. Electronic absorption spectra of iron complexes of nitrocatechol derivatives in aqueous solution of different pH. Derivatives 1,2 , and 3 were $1.0 \mathrm{mM}$, and iron was 0.33 mM. Left: difference spectra in HEPES-saline (pH 7.4); right: spectra in $0.05 \mathrm{M}$ acetate buffer ( $\mathrm{pH} \mathrm{4.5)}$ ) of ironnitrocatechols.

quots $(500 \mu \mathrm{L})$ of iron complexes were frozen in liquid nitrogen and measured under the following conditions: power, $9.8 \mathrm{~mW}$; modulation, $0.64 \mathrm{~T}$; scanning field, $250 \pm$ $200 \mathrm{mT}$; amplitude, $5.0 \times 10^{5}$; time constant, $500 \mathrm{msec}$; sweep time, $1000 \mathrm{sec}$. ESR spectra were analyzed by $\mathrm{S}=5 / 2$ spin Hamiltonian:

$$
H=g_{e} \beta H_{0} S+E\left(S_{x}-S_{y}\right)+D\left(S_{z}^{2}-35 / 12\right)
$$

where $g_{e}$ is 2.00, $\beta$ is the Bohr magneton, $H_{0}$ is the external magnetic field, $S\left(S_{x}, S_{y}, S_{z}\right)$ is the spin operator, and $E$ and $D$ are the zero-field splitting parameters [25].

\section{NMR Spectroscopy}

NMR data were obtaincd at room temperature in 5 - $\mathrm{mm}$ sample tubes by a Bruker AM300-WB spectrometer. Chemical shifts were measured relative to TMS in DMSO and TSP in $\mathrm{D}_{2} \mathrm{O}$. Single pulse sequence was used for frequency region; sweep width, $8000 \mathrm{~Hz}$ (DMSO) and 3600 $\mathrm{Hz}\left(\mathrm{D}_{2} \mathrm{O}\right)$. The other parameters were: acquisition, memory size, 16 kbyte; number of scans, 64; duration of pulse, 8 $\mu \mathrm{sec}$; relaxation delay, $3 \mathrm{sec}$. To study the structure of iron-nitrocatechols, $\mathrm{Ga}^{3+}$ was used as a substitute for $\mathrm{Fe}^{3+}$. The $\mathrm{pD}$ was calculated by $\mathrm{pD}=\mathrm{pH}+0.4$.

\section{RESULTS}

Iron-induced lipid peroxidation was studied using rat liver microsomes (Fig. 2). Microsomes incubated with iron and citrate produced lipid peroxidation, as measured by
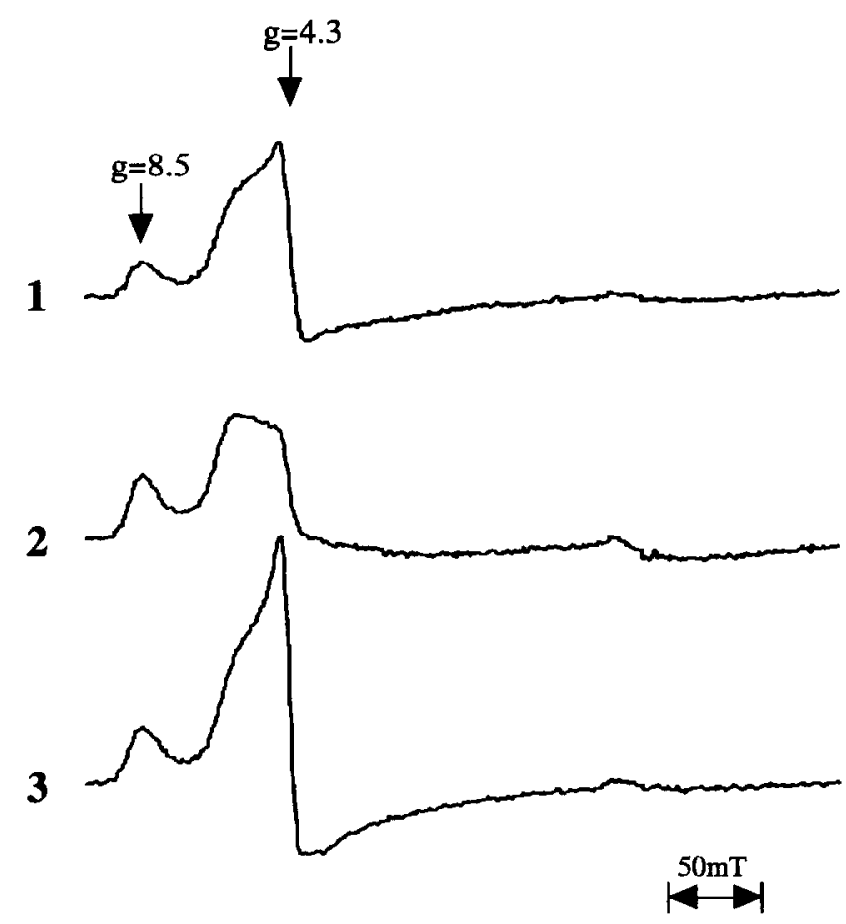

FIG. 6. ESR spectra of iron complexes of nitrocatechol derivatives. The ESR spectra of iron complexes of nitrocatechol derivatives 1,2 , and 3 (iron:derivative $=1: 1$ ) were recorded at $200^{\circ} \mathrm{K}$ in DMSO. The $\mathrm{g}$ values were measured by DPPH as a reference.

TBARS. Control microsomes also produced some TBARS, likely as a result of iron impurities in the microsomes. However, in the presence of nitrocatechol derivatives, iron did not promote lipid peroxidation in microsomes, and the lipid peroxidation was inhibited as compared with the control. Catechol also inhibited lipid peroxidation in the same manner as the derivatives. Using ESR spin-trapping, ironcatechol generated hydroxyl radicals much more strongly than did iron citrate, and iron-nitrocatechol derivative 2 generated a small amount of hydroxyl radicals (Figs. 3 and 4). However, iron complexes of derivatives 1 and $3 \mathrm{did}$ not generate hydroxyl radicals.

The rates of oxidation and reduction were measured in

TABLE 3. Proton chemical shifts of $\mathrm{Ga}^{3+}-$ complexes of nitrocatechol derivatives in DMSO

\begin{tabular}{lccc}
\hline \multirow{2}{*}{${ }^{\mathbf{H}}$ position on } & \multicolumn{3}{c}{ Chemical shift (ppm) } \\
& $\mathbf{1}$ & $\mathbf{2}^{\mathbf{*}}$ & $\mathbf{3}$ \\
\hline $\mathrm{C} 1, \mathrm{C} 5(\mathrm{C} 2 \dagger)$ & $2.37,2.28$ & 2.10 & $1.15,3.40$ \\
$\mathrm{C} 3$ & & 4.19 & \\
$\mathrm{C} 6$ & 7.48 & 2.81 & 7.49 \\
$\mathrm{C} 2^{\prime}, \mathrm{C}^{\prime}$ & $6.66,7.44$ & $6.53,6.83$ & $7.46,7.67$ \\
\hline
\end{tabular}

The proton chemical shifts of $\mathrm{Ga}^{3+}$-complexes of nitrocatechol derivatives in DMSO are presented relative to TMS. The proton positions are presented in Fig. 1 by numbering carbons to which the protons are bound.

* These chemical shifts are keto-type ones of iron-nitrocatechol complex.

$\dagger$ The chemical shift of the proton on $\mathrm{C} 2$ is presented in derivative 3 instead of the proton shift on $\mathrm{C} 5$. 
TABLE 4. Proton chemical shifts of $\mathrm{Ga}^{3+}$-complexes of nitrocatechol derivatives in $\mathrm{D}_{2} \mathrm{O}$ ( $\mathrm{pD} 7.5$ )

\begin{tabular}{lcccccc}
\hline & \multicolumn{5}{c}{ Chemical shift (ppm) } \\
$\begin{array}{l}{ }^{\mathbf{1}} \mathbf{H} \text { position } \\
\text { on }\end{array}$ & $\mathbf{1}$ & $\mathbf{\Delta}$ & $\mathbf{2}$ & $\mathbf{\Delta}$ & $\mathbf{3}$ & $\boldsymbol{\Delta}$ \\
\hline $\mathrm{C} 1, \mathrm{C} 5$ & $2.46,2.43$ & $-0.03,0.00$ & 2.22 & -0.01 & 1.22 & -0.02 \\
$\mathrm{C} 6$ & 7.65 & 0.04 & 2.95 & -0.03 & 7.48 & 0.01 \\
$\mathrm{C}^{\prime}, \mathrm{C6}^{\prime}$ & $6.72,7.51$ & $-0.12,-0.25$ & $6.62,7.02$ & $-0.27,-0.22$ & $7.44,7.84$ & $-0.17,-0.16$ \\
\hline
\end{tabular}

The proton chemical shifts of $\mathrm{Ga}^{3+}$-complexes of nitrocatechol detivatives in water are presented relative to TMS. The proton positions are presented in Fig. 1 by numbering carbons to whiali the protoits ate bound. $\Delta$ is the difference of proton chetuical shifts of $\mathrm{Ga}^{3+}$-nitrocatechols from the nitrocatechols.

HEPES-saline (pH 7.4) at $25^{\circ}$ (Table 1). To measure the reduction rate, dihydrolipoic acid was used as a reducing agent because the reduction by ascorbate or $\mathrm{NADH}$ at $\mathrm{pH}$ 7.4 was too slow to measure by oxygen electrode. The ratios of $k_{\mathrm{Rd}} / k_{\mathrm{Ox}}$, in order of magnitude, were citrate $>$ catechol $\gg$ derivative $2>1,3$.

Iron binding by nitrocatechol derivatives and the physicochemical properties of the ion were studied by UV/vis absorption spectroscopy, ESR, and ${ }^{1} \mathrm{H}$ NMR. When the derivatives were mixed with ferric ion in aqueous solution, the color changed, depending on $\mathrm{pH}$. At a $\mathrm{pH}$ of less than 1 , the iron complexes were bluish light yellow, but as the $\mathrm{pH}$ increased, the color changed to brownish red. In UV/vis absorption spectroscopy of the aqueous solution, the absorbance maximum at $\sim 700 \mathrm{~nm}$ changed to $\sim 550 \mathrm{~nm}$ with increasing $\mathrm{pH}$ from 1.0 to 7.4. Typical absorption spectra at $\mathrm{pH} 4.5$ and 7.4 are shown in Fig. 5. In DMSO, the ferric complexes showed an absorbance maximum at $-700 \mathrm{~nm}$, which was virtually the same as that of aqueous acidic solutions, but the intensity was much stronger than that in aqueous acidic solution. All ferric complexes of nitrocatechol derivatives showed similar characteristics on UV/vis spectroscopy (Table 2). The absorbance maxima and molar extinction coefficients of ferric complexes of derivatives 1 and 3 were very similar, but in aqueous solution, the $a b$ sorption band of iron-derivative $\mathbf{2}$ was in a lower energy region and the molar extinction coefficient was somewhat smaller than those of the others. Using the characteristic visible absorbance of ferric complexes, Job's plotting was done in HEPES-saline ( $\mathrm{pH} \mathrm{7.4)}$ ) and DMSO (data not shown). In the ferric complex of derivative 2 , the molar ratio of iron to the derivative was $1: 3$ at $\mathrm{pH} 7.4$; plotting for derivatives 1 and 3 was not done because the large absorption band of the derivative itself disturbed the measurement. In DMSO, the ratio was 1:1 for all nitrocatechol derivatives, IR spectra of iron complexes of nitrocatechol derivatives obtained as $\mathrm{KBr}$ disk also showed that the $\nu \mathrm{OH}$ ( 3250 and $3500 \mathrm{~cm}^{-1}$ ) of the derivatives disappeared and the carbonyl groups remained (data not shown), which indicates that phenolic oxygens of the derivatives chelated iron and formed catechol-type iron complexes. Since the visible band of iron-catechol exhibits a blue shift depending on the $\mathrm{pH}$ changing the molar ratio of iron to catechol $[14,26]$, we inferred that in aqueous solution iron- nitrocatechol complexes changed the molar ratios of iron to nitrocatechol derivative from 1:1 to $1: 3$ with increasing $\mathrm{pH}$ :

$$
\begin{aligned}
\mathrm{Fe}^{3+}+3 & \text { nitrocat }{ }^{2-} \rightarrow[\mathrm{Fe}(\text { nitrocat })]^{+}+2 \text { nitrocat }^{2-} \\
& \rightarrow\left[\mathrm{Fe}(\text { nitrocat })_{2}\right]^{-}+\text {nitrocat }^{--} \rightarrow\left[\mathrm{Fe}(\text { nitrocat })_{3}\right]^{3-}
\end{aligned}
$$

and the visible absorption band is assigned to a nitrocatecholate $\rightarrow \mathrm{Fe}^{3+}$ charge transfer transition [27].

ESR spectra of iron complexes of the nitrocatechol derivatives were recorded in HEPES-saline $(\mathrm{pH} \mathrm{7.4)}$ and DMSO (Fig. 6) at $200^{\circ} \mathrm{K}$. In both solutions, the complexes mainly showed an ESR signal near $\mathrm{g}=4.3$ as expected for a transition between the middle Kramers' doublet of a rhombic high-spin iron(III) complex. The ESR signal near $\mathrm{g}=4.3 \mathrm{had}$ broad signals on both sides, which suggests that the complexes are not completely rhombic $(E / D<1 / 3)$ [28]. This is also suggested by the fact that a weak ESR signal at lower field from the ground Kramers' doublet had a $g$ value of less than 9.0. All iron complexes of nitrocatechol derivatives were in the ferric high-spin state with nearrhombicity.

For ${ }^{1} \mathrm{H}$ NMR study of the iron complexes, $\mathrm{Ga}^{3+}$ was used as a substitute for $\mathrm{Fe}^{3+}$ because $\mathrm{Ga}^{3+}$ has chemical properties similar to $\mathrm{Fe}^{3+}$ except for the diamagnetism $[29,30]$. In DMSO, ${ }^{1} \mathrm{H}$ NMR of $\mathrm{Ga}^{3+}$ complexes of nitrocatechol derivatives (molar ratio $=1: 1$ ) was measured to confirm the binding sites. In the presence of $\mathrm{Ga}^{3+}$, the proton signal $\left(\mathrm{C}^{\prime}\right.$ and $\left.\mathrm{C}^{\prime}\right)$ of the phenolic hydroxyl group disappeared in derivatives 1 (Fig. 7) and 3, which indicates that phenolic hydroxyl oxygens of the derivatives chelated $\mathrm{Ga}^{3+}$ and formed 1:1 gallium-nitrocatcchol complexes. By intcgration of the ${ }^{1} \mathrm{H}$ NMR signal, it was found that $-70 \%$ of derivative 2 was the kero rype and $\sim 30 \%$ was the enol rype. Proton shifts of $\mathrm{Ga}^{3+}$-nitrocatechol complexes in DMSO are presented in Table $3 . \mathrm{By} \mathrm{Ga}^{3+}$ binding, ring protons $\left(\mathrm{C}^{\prime}{ }^{\prime}\right.$ and $\left.\mathrm{C}^{\prime}\right)$ markedly shifted upfield, and protons of $\mathrm{C} 6$ also shifted in the same direction. Protons (C1 and $\mathrm{C} 5$ for 1 and 2; C1 and C2 for 3) at the end of the substituent shifted slightly. Similar results of proton chemical shifts were reported for enterobactin, a catechol-type siderophore [31]. In $\mathrm{D}_{2} \mathrm{O},{ }^{1} \mathrm{H}$ NMR of $\mathrm{Ga}^{3+}$ complexes of nitrocatechol derivatives was measured at a $1: 3$ molar ratio of iron to the derivatives (Table 4). At $\mathrm{pD} 7.5$, almost all ring protons $\left(C 2^{\prime}\right.$ and $\left.\mathrm{C}^{\prime}\right)$ of the derivatives shifted upfield the same as 


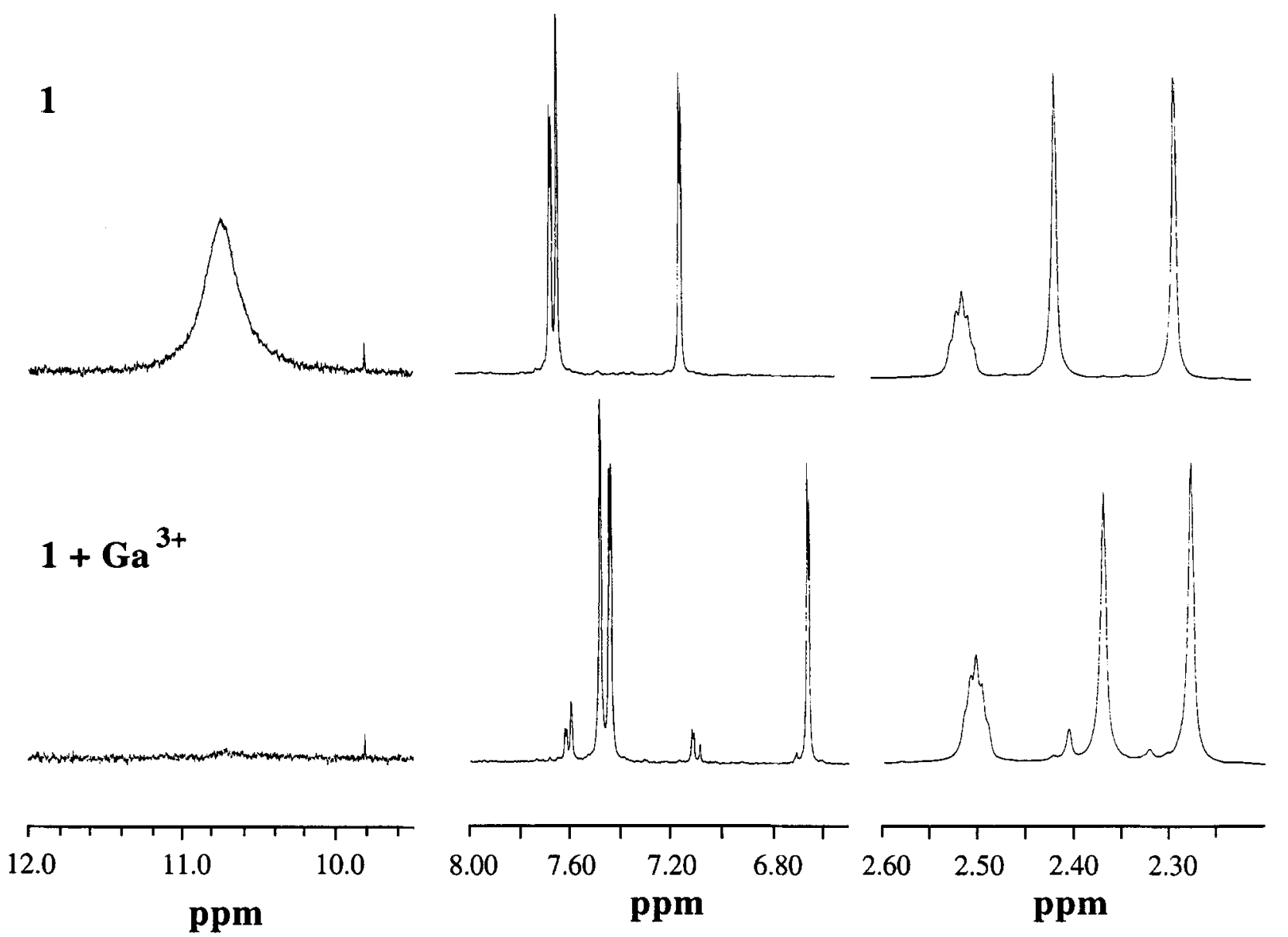

FIG. 7. ${ }^{1} \mathrm{H}$ NMR spectra of nitrocatechol derivative 1 . The NMR spectra of nitrocatechol 1 (20 $\left.\mathrm{mM}\right)$ were recorded at room temperature in DMSO $-\mathrm{d}_{6}$ without and with $\mathrm{Ga}^{3+}(20 \mathrm{mM})$. Chemical shifts were measured using TMS as a reference, with downfield shift taken as positive.

in DMSO, suggesting that in aqueous solution at $\mathrm{pD} 7.5$ all nitrocatechol derivatives form tris(nitrocatecholate) complexes. The methyl protons at the substituent end of nitrocatecholates shifted little because of the catechol-type complex.

We concluded that all nitrocatechol derivatives formed tris(nitrocatecholato)ferrate(III) in aqueous solution at $\mathrm{pH}$ 7.4 (Fig. 8); the iron was high-spin ferric.

\section{DISCUSSION}

We tested the effects of nitrocatechol derivatives on ironinduced free radical reactions. In iron-induced lipid peroxide-dependent lipid peroxidation, catechol and the derivatives showed inhibition in the same manner (Fig. 2), whereas in Fenton-like reactions iron complexes of nitrocatechol derivatives 1 and 3 did not generate hydroxyl radicals, but the iron complex of derivative 2 did (Figs. 3 and 4). Iron-catechol generated hydroxyl radicals more strongly than did citrate. Nitrocatechol derivatives 1 and 3 were the best chelators to protect against iron-induced free radical reactions. It is unlikely that the rates at which the generated $\cdot \mathrm{OH}$ reacts directly to the nitrocatechol derivatives are different between the derivatives because Marcocci et al. reported that derivatives 1 and 2 quenched oxygen free radicals in the same manner [18], and hydroxyl radical can react with almost all molecules with a diffusionlimited rate constant. Therefore, the different effects of catechol and nitrocatechol derivatives are attributed to the chelate structures and redox properties.

To elucidate the coordination structures of iron complexes of nitrocatechol derivatives, we studied the iron complexes in aqueous solution and DMSO. The structures of iron-nitrocatechol derivative complexes were different from iron-catechol complex. Catechol is reported to form tris(catecholato)ferrate(III) with iron at alkaline $\mathrm{pH}$, but around $\mathrm{pH} 7.4$ catechol predominantly forms a 1:2 complex with iron $[14,26,32]$. The nitrocatechol derivatives formed $1: 3$ complexes with iron at $\mathrm{pH} 7.4$ (Fig. 8). The nitrocatechol derivatives have lower $\mathrm{pK}_{a}$ values of the phenolic hydroxyl groups than catechol because of an electrophilic nitro group in dihydroxylbenzene moiety [18] and can make $1: 3$ complexes with iron at $\mathrm{pH} 7.4$, which is more beneficial to sequester iron and prohibit the iron from the approach of 


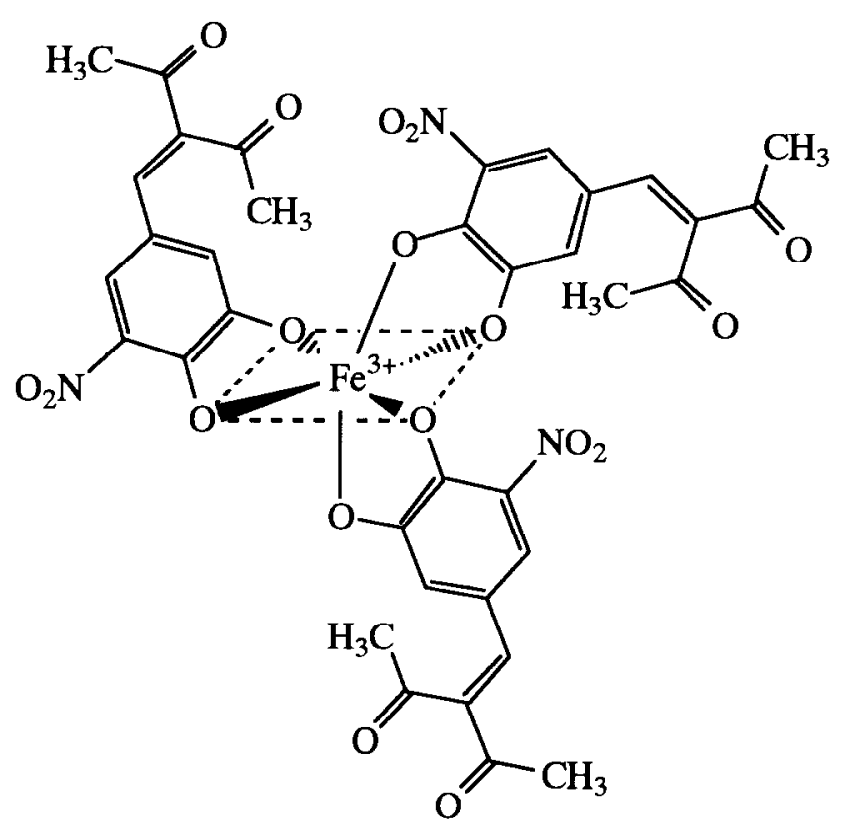

FIG. 8. Proposed structure of the iron complex of nitrocatechol derivative 1 at $\mathrm{pH} 7.4$.

the reactants in biological systems. In a molecule of $1: 2$ iron-catechol complex is a space through which a small reactant such as hydrogen peroxide can approach the chelated iron, but lipid peroxides, which are larger, do not approach the catalytic iron by the steric effect [33].

The redox properties of the iron complexes are important in the free radical generation by transition metals. Considering the equilibrium of ferric and ferrous complexes:

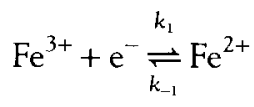

the ratio of $k_{1} / k_{-1}$ is related to the reduction potential, $\Delta E$ $=-\Delta \mathrm{G} / \mathrm{F}=\mathrm{RT} \ln \left(k_{1} / k_{-1}\right) / \mathrm{F}$, were $F$ is the Faraday constant. Using the ratio $k_{\mathrm{Rd}} / k_{\mathrm{Ox}}$ as a substitute for $k_{1} / k_{-1}$, the $k_{\mathrm{Rd}} / k_{\mathrm{Ox}}$ may also be related to the reduction potential. We evaluated the redox properties of the iron complexes by the $k_{\mathrm{Rd}} / k_{\mathrm{Ox}}$ ratios (Table 1 ). Iron complexes of all nitrocatechol derivatives had much lower ratios than iron citrate, which is consistent with low reduction potentials of catechol-type iron complexes [11-13]. Iron-catechol showed a higher reduction potential than iron-nitrocatechols because of the different coordination structure. Iron complexes of nitrocatechol derivatives 1 and 3 showed the same $k_{\mathrm{Rd}} / k_{\mathrm{O} \times}$ ratio, while iron complex of nitrocatechol derivative $2 \mathrm{had}$ a higher ratio, which suggested that iron-nitrocatechol 2 has a higher reduction potential than the other iron-nitrocatechols ( 1 and 3 ). It is reported that iron phenolate with conjugated substituent has a lower reduction potential than the corresponding iron phenolate without the conjugation [34]. Nitrocatechol derivatives 1 and 3 have conjugation substitutes, but derivatives 2 does not. This fact is reasonably explained by molecular orbital considerations, that is, a catechol with a conjugation substituent has higher energy of HOMO than the corresponding one without the conjugation, and iron d oribtals in catechol-type iron complexes are sensitive to the HOMO $[35,36]$. As shown in the $\lambda_{\max }$ data (Table 2), the energy gap of ligand-to-metal charge transfer $\left(\pi \rightarrow \mathrm{d}_{\pi}\right)$ of iron-nitrocatechol 2 was larger than those of iron-nitrocatechols 1 and 3. Therefore, we inferred that iron-nitrocatechol 2 has a higher reduction potential than iron-nitrocatechols 1 and 3, and generated hydroxyl radical in a Fenton-like reaction. The reaction rates of ligand exchange of iron-nitrocatechols may not be so important because iron chelated by the derivatives was high-spin ferric in iron-nitrocatechols (Fig. 6), and all the high-spin iron complexes may be ligand-exchange-labile [37].

In this study we showed that nitrocatechol derivatives with a conjugation structure are promising candidates for therapy of so-called "free radical diseases." In addition to the radical scavenging effects, they have strong thermodynamic stabilities for iron, and the chelated iron has no catalytic activity for free radical generation because the iron complexes prefer the ferric state to the ferrous one due to the low reduction potentials.

This work was supported by National Institutes of Health (CA 47597) and Orion-Farmos Pharmaceuticals (Espoo, Finland). We thank Dr. M. Mizuno for help with chemical interpretation and Dr. N. Fujitake for IR spectroscopy.

\section{References}

1. Halliwell B and Gutteridge JMC, Free Radicals in Biology and Medicine. Clarcndon, Oxford, 1989.

2. Millar DM, Buettner GR and Aust SD, Transition metals as catalysts of "autoxidation" reactions. Free Radic Biol Med 8: 95-108, 1990.

3. Stadtman ER, Metal ion-catalyzed oxidation of proteins: Biochemical mechanism and biological consequences. Free Radic Biol Med 9: 315-325, 1990.

4. Lauffer RB, Iron and Human Disease. CRC Press, Boca Raton, 1992.

5. Halliwell B and Gutteridge JMC, Role of free radicals and catalytic metal ions in human disease: An overview. Methods Enzymol 186: 1-85, 1990.

6. Yamazaki I and Piette LH, ESR spin-trapping studies on the reaction of $\mathrm{Fe}^{2+}$ ions with $\mathrm{H}_{2} \mathrm{O}_{2}$-reactive species in oxygen toxicity in biology. J Biol Chem 265: 13589-13594, 1990.

7. Yamazaki I and Piette LH, EPR spin-trapping study on the oxidizing species formed in the reaction of the ferrous ion with hydrogen peroxide. J Am Chem Soc 113: 7588-7593, 1991.

8. Rush JD, Cyr JE, Zhao ZW and Bielski BHJ, The oxidation of phenol by ferrate(VI) and ferrate(V). A pulse radiolysis and stopped-flow study. Free Radic Res 22: 349-360, 1995.

9. Jacob A and Worwood M, Iron in Biochemistry and Medicine. Academic Press, London, 1980.

10. Williams RJP, An Introduction to the Nature of Iron Transport and Storage. CRC Press, Boca Raton, 1990.

11. Buettner GR, The pecking order of free radicals and antioxidants: Lipid peroxidation, $\alpha$-tocopherol, and ascorbate. Arch Biochem Biophys 300: 535-543, 1993.

12. O'Brien IG, Cox GB and Gibson F, Enterochelin hydrolysis 
and iron metabolism in Escherichia coli. Biochim Biophys Acta 237: 537-549, 1971.

13. Cooper SR, McArdle JV and Raymond KN, Siderophore electrochemistry: Relation to intracellular iron release mechanism. Proc Natl Acad Sci USA 75: 3551-3554, 1978.

14. Avdeef A, Sofen SR, Bregante TL and Raymond KN, Coordination chemistry of microbial iron transport compounds. 9. Stability constants for catechol models of enterobactin. J Am Chem Soc 100: 5362-5370, 1978.

15. Raymond KN, Isied SS, Brown LD, Fronczek FR and Nibert $\mathrm{JH}$, Coordination isomers of biological iron transport compounds. VI. Models of the enterobactin coordination site. A crystal field effect in the structure of potassium tris(catecholato)chromate(III) and -ferrate(III) sesquihydrates, $\mathrm{K}_{3}\left[\mathrm{M}_{2}\left(\mathrm{O}_{2} \mathrm{C}_{6} \mathrm{H}_{4}\right)_{3}\right] \cdot 1.5 \mathrm{H}_{2} \mathrm{O}, \mathrm{M}=\mathrm{Cr}$, Fe. J Am Chem Soc 98: $1767-1774,1976$

16. Matzanke BF, Mueller-Matzanke G and Raymond KN, Siderophore-Mediated Iron Transport. VHC Publishers, New York, 1989.

17. Suzuki YJ, Tsuchiya M, Asaad S, Kagan VE and Packer L, Antioxidant properties of nitecapone (OR-462). Free Radic Biol Med 13: 517-525, 1992.

18. Marcocci L, Suzuki YJ, Tsuchiya M and Packer L, Antioxidant activity of nitecapone and its analog OR-1246: Effect of a structural modification on antioxidant action. Methods Enzymol 234: 538-553, 1994.

19. Haramaki N, Stewart DB, Aggarwal S, Kawabata $T$ and Packer $\mathrm{L}$, Role of ascorbate in protection by nitecapone against cardiac ischemia-reperfusion injury. Biochem Pharmacol 50: 839-843, 1995.

20. Green MJ and Hill AO, Chemistry of dioxygen. Methods Enzymol 105: 3-22, 1984.

21. Hogeboom GH, Fractionation of cell components of animal tissues. Mcthods Enzymol 1: 16 19, 1955.

22. Lowry $\mathrm{OH}$, Rosebrough NJ, Farr AL and Randall RJ, Protein measurement with the Folin phenol reagent. J Biol Chem 193: 265-275, 1951.

23. Ohkawa $\mathrm{H}$, Ohishi $\mathrm{N}$ and Yagi $\mathrm{K}$, Assay for lipid peroxides in animal tissues by thiobarbituric acid reaction. Anal Biochem 95: 351-358, 1979.

24. Kawabata T, Tritschler H-J and Packer L, Reaction of $(R, S)$-dihydrolipoic acid and homologs with iron. Methods Enzymol 251: 325-332, 1995.

25. Wertz JE and Bolton JR, Electron Spin Resonance. Elementary
Theory and Practical Applications. Chapman \& Hall, New York, 1986.

26. Aplincourt M, Gerard C, Hugel RP, Pierrard JC, Rimbault J, Bertrandie A, Magny B and Siret PJ, Metal cation-ligand interactions of catechols of biological importance. I. Stability of iron(III) dihydroxybenzamide complexes which are related to cephalosporins bearing at $\mathrm{C}^{\prime}$ a catechol group. Polyhedron 11: 1161-1168, 1992.

27. Salama S, Stong JD, Neiland JB and Sprio TG, Electronic and resonance raman spectra of iron(III) complexes of enterobactin, catechol, and $N$-methyl-2,3-dihydroxybenzamide. Biochemistry 17: 3781-3785, 1978.

28. Aasa R, Powder line shapes in the electron paramagnetic resonance spectra of high-spin ferric complexes. J Chem Phys 52: 3919-3930, 1970.

29. Borgias BA, Barclay SJ and Raymond KN, Structural chemistry of gallium(III). Crystal structures of $\mathrm{K}_{3}$ [Ga(catecholate) $\left.{ }_{3}\right] \cdot 1.5 \mathrm{H}_{2} \mathrm{O}$ and [Ga[benzohydroxamate) $\left.{ }_{3}\right] \cdot \mathrm{H}_{2} \mathrm{O} \cdot \mathrm{CH}_{3} \mathrm{CH}_{2} \mathrm{OH}$. J Coord Chem 15: 109-123, 1986.

30. Cotton FA and Wilkinson G, Advarked Inorganic Chemistry. John Wiley, New York, 1988.

31. Llinas M, Wilson DM and Neilands JB, Effect of metal binding on the conformation of enterobactin. A proton and carbon-13 nuclear magnetic resonance study. Biochemistry 12: 3836-3843, 1973.

32. Mentasti E and Pelizzetti E, Reaction between iron(III) and catechol (o-dihydroxybenzene). Part 1. Equilibria and kinetics of complex formation in aqueous acid solution. J Chem Soc Dalton Trans 2605-2614, 1973.

33. Traylor TG and Ciccone JP, Mechanism of reaction of hydrogen peroxide and hydroperoxides with iron(III) porphyrins. Effects of hydroperoxide structure on kinetics. J Am Chem Soc 111: 8413-8420, 1989.

34. Ramesh $\mathrm{K}$ and Mukherjee $\mathrm{R}$, Trends in the spectral and redox potential data of mononuclear iron(III) $(S=5 / 2)$ phenolate complexes. J Chem Soc Dalton Trans 83-89, 1992.

35. Gordon DJ and Fenske RF, Theoretical study of o-quinone complexes of iron. Inorg Chem 21: 2916-2923, 1982.

36. Pyrz JW, Roe AL, Stern LJ and Que LJ, Model studies of iron-tryosinate protein. J Am Chem Soc 107: 614-620, 1985.

37. Basolo F and Pearson RG, Mechanisms of Inorganic Reactions: A Study of Metal Complexes in Solution. John Wiley, New York, 1967. 